\title{
Cytomorphological and Morphometric Analysis of 22 Cases of Rosai-Dorfman Disease: A Large Series from a Tertiary Care Centre
}

\author{
Saumyaranjan Mallick Ranajoy Ghosh Venkateswaran K. lyer Deepali Jain \\ Sandeep R. Mathur \\ Department of Pathology, All India Institute of Medical Sciences, New Delhi, India
}

\section{Key Words \\ Cytomorphology $\cdot$ Morphometry $\cdot$ Rosai-Dorfman disease}

\begin{abstract}
Background: Rosai-Dorfman disease (RDD) is a rare benign idiopathic histiocytic proliferation. Most commonly reported cases are lymph nodal. Only $30-40 \%$ of cases occur in extranodal sites. Although the morphological features of RDD are well documented, there is limited information about the morphometric variations in the histiocytes of this entity. Method: Twenty-two cases of RDD diagnosed on fine-needle aspiration cytology (FNAC) were retrieved from the archives. Both Papanicolaou- and May-Grünwald-Giemsastained slides were available for evaluation in all cases. Nuclear area, diameter and histiocyte size were measured taking reactive histiocytes as controls. Results: Among the 22 patients (male/female ratio 3:2; age range 5-55 years, mean 26 years), 3 cases were extranodal and 19 cases were nodal. The nodal sites included cervical, axillary, inguinal and submandibular lymph nodes. The extranodal sites were the retroperitoneum, mediastinum and skin. The most common clinical presentation was enlarged lymph nodes. Cytological features included numerous large benign histiocytes with emperipolesis. All the morphometric parameters were sig-
\end{abstract}

nificantly $(p<0.01)$ higher in RDD histiocytes than in histiocytes in the reactive lymph node. Conclusions: In view of the rarity of the disease and the variable clinical presentation in RDD, accurate diagnosis is necessary. This is the first study to document the morphometric parameters of RDD histiocytes and their comparison with histiocytes in the reactive lymph node.

(c) 2013 S. Karger AG, Basel

\section{Introduction}

Rosai-Dorfman disease (RDD) or sinus histiocytosis with massive lymphadenopathy is a benign histiocytic proliferation, characterized by massive lymphadenopathy with or without extranodal manifestation. This entity was first described by Rosai and Dorfman in 1969 [1]. The condition mostly occurs in adolescent and young adults in the second decade of life [2]. Lymphnodal mass is the most common presentation. The extranodal manifestations are not uncommon and account for around 30-40\% of all cases [3]. The involved sites encompass almost every system including the digestive, skeletal, respiratory and central nervous systems [4-7]. Due to varied clinical manifestation and rarity, it can

\section{KARGER}

E-Mail karger@karger.com www.karger.com/acy
(C) 2013 S. Karger AG, Base

0001-5547/13/0576-0625\$38.00/0
Correspondence to: Dr. Sandeep R. Mathur

Department of Pathology

All India Institute of Medical Sciences

Ansari Nagar, New Delhi 110029 (India)

E-Mail mathuraiims@gmail.com 

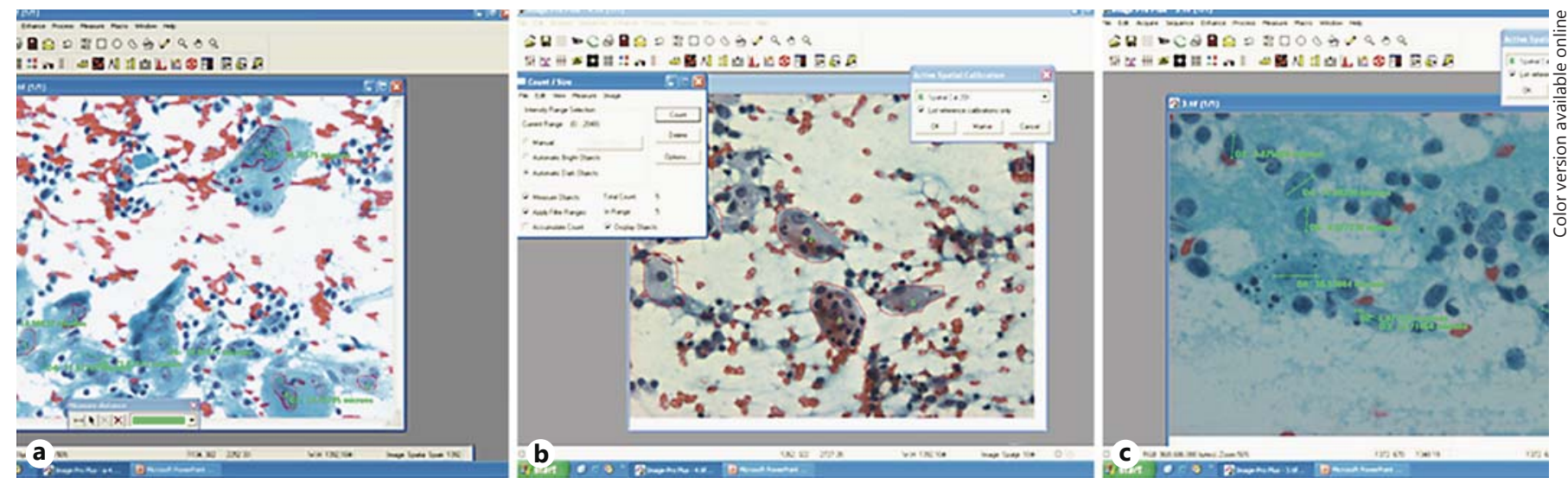

Fig. 1. Photomicrographs (screen shots). Histiocyte nuclei (a) and cytoplasmic border (b) outlined with red to measure area through Image-Pro Plus software. c Nuclear diameter of reactive histiocytes.

mimic other causes of massive lymphadenopathy like lymphoma, histiocytic sarcoma, tuberculosis and metastasis. Extranodal RDD involving soft tissue may mimic pseudotumor clinically [8]. Fine-needle aspiration cytology (FNAC) is an effective diagnostic modality for this condition. There is no specific serological marker for diagnosis. However, patients have an elevated erythrocyte sedimentation rate, neutrophilia and hypergammaglobulinemia [9]. The disease is idiopathic and exact etiology is not known. It usually has a self-limiting course with a good prognosis. Cases with a variable clinical course and multiple recurrences have also been reported. However, the overall mortality is less than 7\% [10]. The hallmark of RDD is extensive histiocytic proliferation with emperipoelosis. The aim of this study was to highlight the utility of both FNAC as well as morphometry in characterizing the histiocytes of RDD and differentiate these cells from that of reactive lymph node hyperplasia. To the best of our knowledge, ours is the first report in the literature where the utility of morphometry is being documented in characterizing RDD histiocytes on cytosmears.

\section{Materials and Methods}

This was a retrospective study in which cases diagnosed as RDD on FNAC between 1998 and 2012 were included. FNAC smears from 22 cases of RDD were included. The smears of 5 cases of histopathologically documented reactive lymph node with sinus histiocytes were also included for morphometric comparison.

Detailed cytological examination was carried out in both Papanicolaou (PAP)- and May-Grünwald-Giemsa (MGG)-stained slides, which were both available for all the cases.
The number of lymphocytes and plasma cells present inside the histiocytes with emperipolesis were quantified in 50 histiocytes of each case of RDD. The mean lymphocyte and plasma cell count per histiocyte was determined in each case.

Histiocytes were categorized into 4 groups based on the extent of emperipolesis:

Group 1: 1-5 lymphocytes or plasma cells/histiocytes

Group 2: 6-10 lymphocytes or plasma cells/histiocytes

Group 3: 11-15 lymphocytes or plasma cells/histiocytes

Group 4: >16 lymphocytes or plasma cells/histiocytes.

For morphometric analysis, the PAP smears were scanned at low magnification $(\times 4)$ to locate areas of highest histiocyte density and emperipolesis. A minimum of five digital photographs were captured using a light microscope $(\times 20$ objective; model BX50, Olympus Corporation, Tokyo, Japan). The images were stored in TIFF format. Detailed morphometric measurements (histiocyte nuclear area, largest nuclear diameter and histiocytes size) were done by image analysis (Image-Pro Plus software optimus 6, Media Cybernetics Corporation, Warrendale, Pa., USA). Appropriate calibration of the system was done before measurement. The histiocyte nuclei were outlined by an automatic or semiautomatic tracing system. A minimum of 100 nonoverlapping nuclei of representative cells were traced. For histiocyte size (cytoplasmic area), 30 clearly defined cells with prominent cytoplasmic borders were taken (fig. 1). Area and diameter of the outlined nuclei were measured in micron. Data obtained were transported to Microsoft Excel.

The data was analyzed by STATA 9 (Stata Corporation, College Station, Tex., USA). Mean (standard deviation)/median (minimum, maximum) were analyzed for each parameter in each group. Normality of each variable was checked by means of the ShapiroWilk test. Normally distributed variable (nuclear diameter) was compared by independent Student $t$ test and non-normally distributed variable (nuclear area and histiocyte size) by the Wilcoxon rank-sum (Mann-Whitney U) test. $\mathrm{p}<0.05$ was taken as statistically significant. 
Table 1. Summary of clinical parameters in different cases of RDD

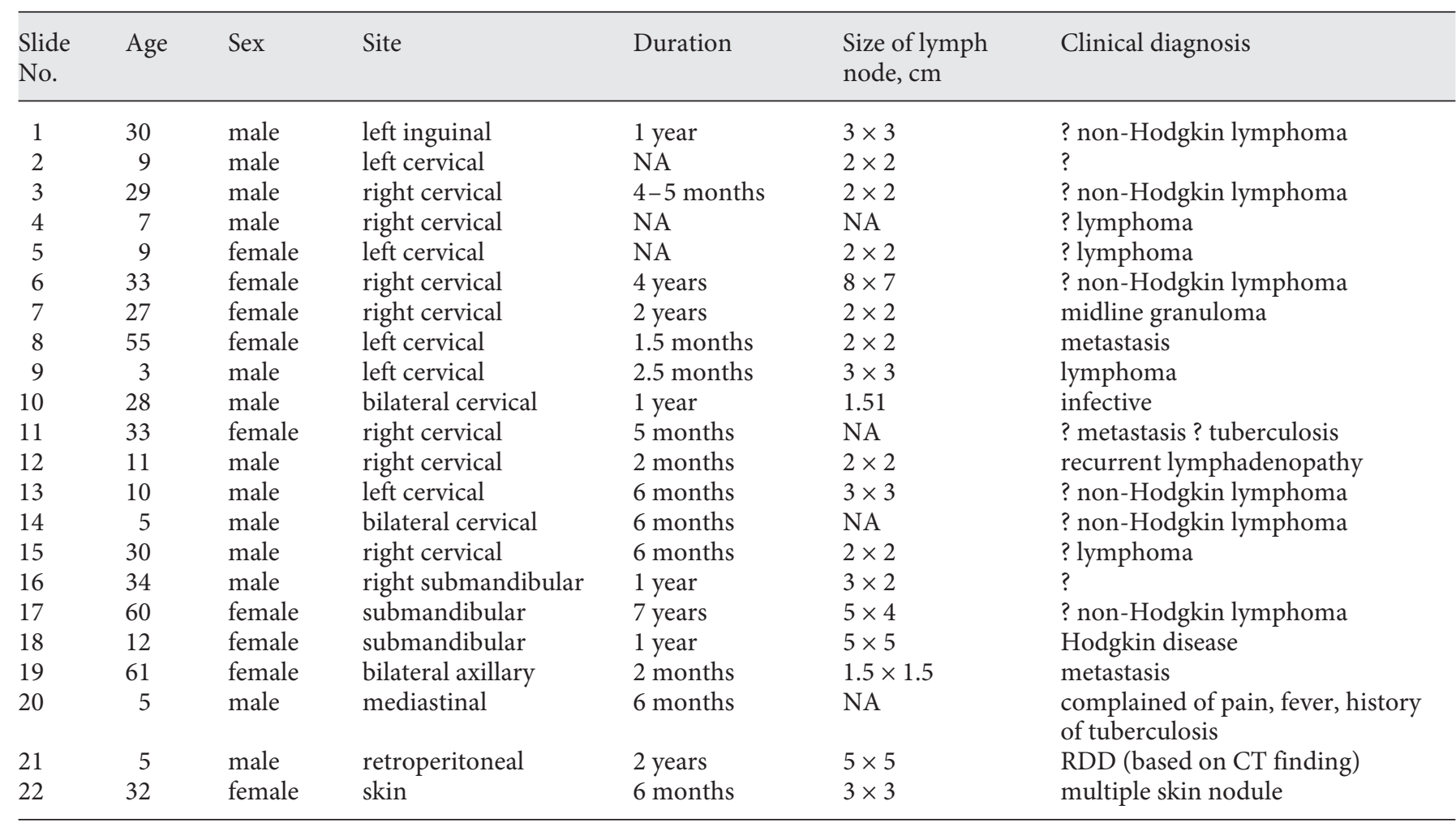

\section{Results}

The clinical presentation of these cases is depicted in table 1 . A total of 22 cases were studied. The mean age of presentation was 26 years and the median 20 years (age range $5-55$ years). There was male predominance with a male-to-female ratio of 3:2. The most common clinical presentation was lymphadenopathy seen in 19 (86\%) cases, followed by fever and constitutional symptoms. Three cases of extranodal RDD presented as a mediastinal mass, a retroperitoneal mass and a skin nodule. Cervical lymph node was involved in 12 cases, followed by 3 submandibular, 1 bilateral axillary and 1 inguinal lymph node. The most common clinical differential was lymphoma. The size of the lymph nodes varied from 2 to $4 \mathrm{~cm}$.

Cytologically, the smears showed proliferation of large histiocytes with numerous prominent engulfed intracytoplasmic intact lymphocytes and/or plasma cells (emperipolesis). The histiocytes had abundant cytoplasm with large nuclei and conspicuous nucleoli. The cells with emperipolesis demonstrated a clear zone around the engulfed cells (fig. 2). The number of cells within the histio-
Table 2. Distribution of pattern of emperipoleisis in different cases

\begin{tabular}{llc}
\hline Group & Predominant pattern & $\begin{array}{l}\text { Number of } \\
\text { cases }\end{array}$ \\
\hline I & $1-5$ lymphocytes/plasma cells & 4 \\
II & $6-10$ lymphocytes/plasma cells & 13 \\
III & $11-15$ lymphocytes/plasma cells & 3 \\
IV & $>16$ & 2 \\
\hline
\end{tabular}

cyte varied from case to case (table 2). The background showed an admixture of centrocytes, centroblasts and immunoblasts. Few atypical features were seen in the histiocytes; these included multinucleate giant cells, erythrophagocytosis, clover-leaf nuclei, large bizzare nuclei and large kidney-shaped nuclei (fig. 3).

Morphometric parameters show the mean nuclear diameter of the RDD histiocytes was $16.7 \mu \mathrm{m}$ compared with the diameter of reactive histiocytes i.e. $10.1 \mu \mathrm{m}$, which was statistically significant $(\mathrm{p}<0.01)$. The median nuclear area in RDD histiocytes was $163.4 \mu \mathrm{m}^{2}$ and in re- 
Fig. 2. Photomicrograph shows large histiocytes with intracytoplasmic (emperipolesis) lymphocytes and plasma cells (>15/histiocytes). a PAP. $\times 100$. b MGG. $\times 100$. c Smear shows numerous histiocytes with few showing emperipolesis, most show $<5$ cells/histiocytes. PAP. $\times 100$. d Smear from reactive lymph node histiocytes with nuclear debris (phagocytosis). PAP. $\times 200$.
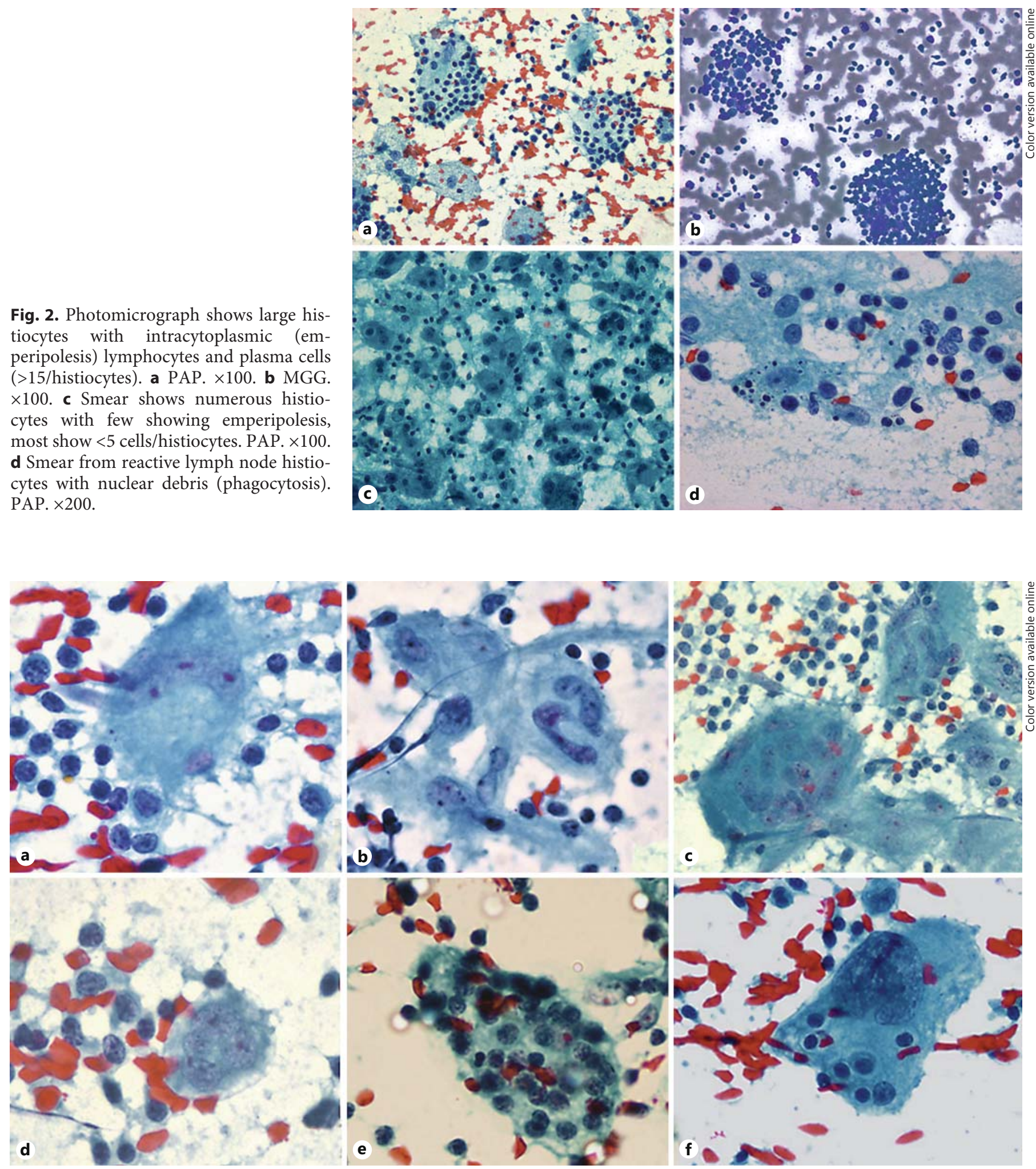

Fig. 3. Photomicrograph. a, b Histiocytes with large kidney-shaped nuclei. PAP. $\times 400$. c Multinucleate giant cells. PAP. $\times 400$. d Cloverleaf nuclei. PAP. $\times 400$. e Erythrophagocytosis. PAP. $\times 400$. $\mathbf{f}$ Large bizarre nuclei. PAP. $\times 400$. 


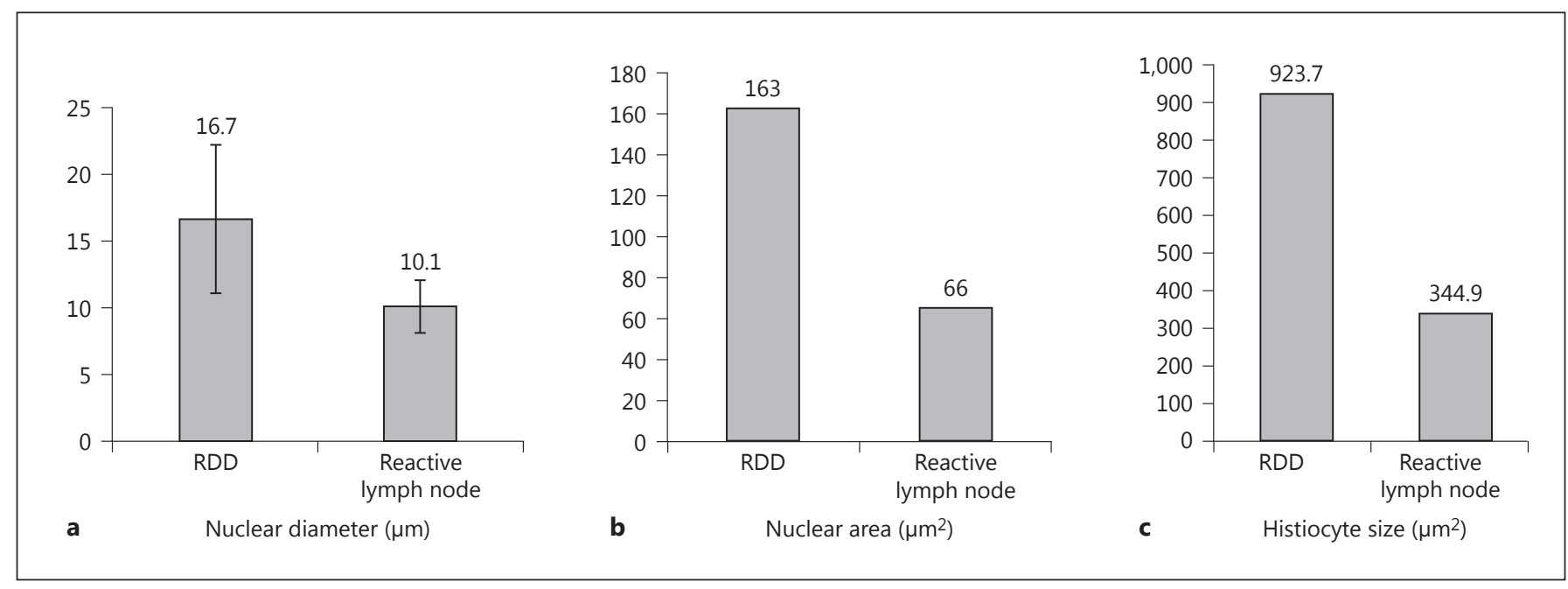

Fig. 4. Comparison between reactive and RDD lymph node histiocytes of mean nuclear diameter (a), median nuclear area (b) and median histiocyte area $(\mathbf{c})$. All parameters were significantly higher in RDD than in the reactive lymph node.

Table 3. Morphometric parameters between histiocytes of RDD and that of reactive lymph node hyperplasia

\begin{tabular}{lccc}
\hline & RDD histiocyte & Reactive histiocyte & p value \\
\hline Mean nuclear diameter \pm SD, $\mu \mathrm{m}$ & $16.7 \pm 5.5$ & $10.1 \pm 1.96$ & $<0.01$ \\
Median nuclear area (min-max), $\mu \mathrm{m}^{2}$ & $163.4(80.9-553.3)$ & $66.14(36.9-145.8)$ & $<0.001$ \\
Median histiocyte area (min-max), $\mu \mathrm{m}^{2}$ & $923.7(195-23,000)$ & $344.9(142-569)$ & $<0.001$ \\
\hline
\end{tabular}

All the parameters are significantly higher in RDD histiocytes than that of reactive lymph nodes.

active histiocytes $66.14 \mu \mathrm{m}^{2}$, which was statistically significant $(\mathrm{p}<0.001)$. Similarly, RDD histiocytes were significantly greater in size $(\mathrm{p}<0.001)$ than those in the reactive lymph nodes (fig. 4 , table 3 ).

\section{Discussion}

RDD remains an enigmatic condition with a variable clinical presentation and course (table 4). It can involve almost every organ and usually has a benign clinical course. However, involvement of extranodal sites like the liver, lower respiratory tract and kidneys are reported to be associated with a poor prognosis [3]. There is only a single published case describing development of histiocytic sarcoma after 4 years of RDD [28].

Although the etiology of RDD is not completely known, viral infections are the most commonly impli- cated causative agents. Human herpes virus 6 [29], parvovirus B19 [30], Simian virus 40 and polyoma virus [31] have been described by various authors as etiologic agents. The known association of human herpes virus with many reactive lymphoid disorders renders this finding nonspecific. The high titers of Klebsiella reported may be a coincidental infection [32]. An association with immunological diseases like systemic lupus erythematosus and arthritis has also been described $[24,27]$. The presence of hypergammaglobulenemia and IgG-positive plasma cells supports the immunological hypothesis [9].

Immunohistochemically, the histiocytes in RDD are positive for CD68 and S100 but negative for CD1a and langerin which help to differentiate RDD from Langerhans cell histiocytosis. Histiocytes can also be seen prominently in reactive lymph nodes. Several authors have reported the utility of morphometry in differentiating benign from malignant cells in various organs like 
Table 4. Summary of organ-wise clinical presentation in RDD

\begin{tabular}{|c|c|c|}
\hline Site & Author, year, reference & Clinical presentation \\
\hline Central nervous system & Sundaram, 2011 [7] & dura base mass, spinal mass, skull bone erosion, intraparenchymal mass \\
\hline Eye & Payne et al., 2011 [11] & lacremal gland, chorodal melanoma, uveitis \\
\hline Paranasal sinus & Avelino et al., 2012 [13] & sinonasal polyp \\
\hline Salivary gland & Güven et al., 2007 [14] & hypoechoeic heterogeneous mass in parotid and submandibular gland \\
\hline Larynx & Illing and Halum, 2012 [15] & dystonia, airway obstruction \\
\hline Lung & Ji et al., 2012 [17] & mass, pleural effusion, pleural thickening \\
\hline Heart & Yontz et al., $2012[18]$ & intra-arterial septum, extending to both atria \\
\hline Breast & Gwin et al., 2011 [19] & mass \\
\hline Gastrointestinal & Long et al., 2007 [20] & sigmoiditis, diverticulosis, polyp \\
\hline Pancreas & Romero et al., 2012 [21] & mass \\
\hline Renal & Tabata et al., $2012[22]$ & kidney mass, urethral obstruction \\
\hline Congenital & Chow et al., 2009 [26] & anemia, thrombocytopenia, hepatomegaly \\
\hline Others & Kaur et al., 2005 [27] & amyloidosis, systemic lupus erythematosus \\
\hline
\end{tabular}

the liver and thyroid as well as in effusions (pleural fluid) [33-35].

We have quantified and compared the cell dimensions and nuclear dimensions of RDD histiocytes with those in the reactive lymph nodes. To the best of our knowledge, no published study yet exists that has morphometrically analyzed the histiocytes of these two entities. Variables like processing, fixation artifacts, staining quality and the morphometric technique used can influence quantitative estimations. Alcohol-fixed FNAC smears are therefore better suited than histological sections to perform such an assessment. The average reported diameter of monocyte/ macrophages and alveolar macrophages is $15-30 \mu \mathrm{m}$ and $21.2 \mu \mathrm{m}$, respectively [36,37]. In our study, the mean nuclear diameter of histiocytes of reactive lymph nodes was significantly smaller than that of RDD histiocytes (10.1 vs. $16.7 \mu \mathrm{m}, \mathrm{p}<0.01$ ). The median area of RDD histiocytes is much larger with a wide variation ranging from 195 to $23,000 \mu \mathrm{m}^{2}$, compared to that of reactive histiocytes $\left(142-569 \mu \mathrm{m}^{2}, \mathrm{p}<0.001\right)$.

We did not find any relevant morphometric study regarding reactive histiocytes in lymph nodes; however, the study by Kram et al. [38] compared the signet-ring adenocarcinoma cells and foamy histiocytes in the stomach on endoscopic biopsies. They found a significant difference between the two cells in regard to mean nuclear area (34.25 and $25.41 \mu \mathrm{m}^{2}$, respectively) and mean nuclear breadth (5.82 and $4.99 \mu \mathrm{m}$, respectively).They proposed a nuclear area value of $25 \mu \mathrm{m}^{2}$ as a cut-off level between signet-ring cell adenocarcinoma cells and foamy macrophages on endoscopic biopsies.

Due to variable clinical presentation and histiocytic proliferation, RDD can be confused with other disorders like Langerhans cell histiocytosis, Hodgkin disease lymphoma, histiocytic sarcoma, Gaucher's disease and mostly metastatic carcinoma. RDD histiocytes, unlike those in the reactive lymph nodes, may display atypical nuclear features like large, clover-leaf and kidney-shaped nuclei, which were also observed in our study. Erythrophagocytosis has been reported to help in differentiating Langerhans cell histiocytosis from RDD; we found this feature in two of our cases [39].

In our study, most cases showed a mean of 5-15 lymphocytes and plasma cells per histiocyte. Only two cases had a count of $>15$ per histiocyte. Those with the highest numbers were associated with a larger size. Though emperipolesis of the large benign histiocytes is a characteristic feature of RDD, this is not documented in all cases. It can appear at all stages of the disease process in the same patient. Iyer et al. [40] described a variable degree of emperipolesis in serial biopsies from a single patient over a period of time. A predominance of foamy histiocytes without obvious emperipolesis was observed in rapidly enlarging lymph nodes; this finding was obvious dur- 
ing the stable phase of the disease. This variation indicates the evolution of the whole disease process over time and may be explained by the diverse cytokine milieu. Sampling of tissues during the stable phase of the disease may therefore yield diagnostically useful material whereas sampling during exacerbation and involution phases may yield tissues inadequate for definitive diagnosis. To validate this hypothesis, we counted the mean number of histiocytes and observed that there was indeed a significant variation in emperipolesis from case to case.

Immunocytochemistry/histochemistry is very useful, but mostly in cases of cytology preparation where alcohol-fixed smears or cell blocks are not always available. Morphometry is also very cost-effective and can be performed with both the MGG and PAP smears. It can be performed using the freely available Image J software. In small centers where immunohistochemistry is not available, morphometry is a very simple and accurate aid for diagnosis.

To conclude, in this study, for the first time, a combined cytological and morphometric evaluation objectively highlighted a significant difference between the histiocytes of reactive lymph nodes and those of $\mathrm{RDD}$ on cytosmears. Awareness of the morphologic and morphometric variations in the cells and in the nuclei of the histiocytes of this entity may be useful in FNAC diagnosis of this disease. The smaller sample size (controls) and the lack of comparison between nodal and extranodal RDD constituted important drawbacks of our study. Larger prospective studies on RDD (both nodal and extranodal) in the near future are needed to substantiate our observations and to understand the biology of the disease process.

\section{References}

1 Rosai J, Dorfman RF: Sinus histiocytosis with massive lymphadenopathy. A newly recognized benign clinicopathological entity. Arch Pathol 1969;87:63-70.

2 Sanchez R, Rosai J, Dorfman R: SHML: an analysis of 113 cases with special emphasis on its extranodal manifestations. Lab Invest 1977;36:349-350.

3 Foucar E, Rosai J, Dorfman R: Sinus histiocytosis with massive lymphadenopathy (RosaiDorfman disease): review of the entity. Semin Diagn Pathol 1990;7:19-73.

4 Goel MM, Agarwal PK, Agarwal S: Primary Rosai-Dorfman disease of bone without lymphadenopathy diagnosed by fine needle aspiration cytology. A case report. Acta Cytol 2003;47:1119-1122.

$>5$ Lauwers GY, Perez-Atayde A, Dorfman RF, Rosai J: The digestive system manifestations of Rosai-Dorfman disease (sinus histiocytosis with massive lymphadenopathy): review of 11 cases. Hum Pathol 2000;31:380-385.

6 Ji H, Zhang B, Tian D, et al: Rosai-Dorfman disease of the lung. Respir Care 2012;57: 1679-1681.

7 Sundaram C: Rosai-Dorfman disease and neurological manifestations. Neurol India 2011;59:329-330.

$>8$ Nayler SJ, Cooper K: Inflammatory pseudotumour and Rosai-Dorfman disease of soft tissue. J Clin Pathol 1997;50:620-621.

$>9$ Naidu RK, Urken ML, Som PM, et al: Extranodal head and neck sinus histiocytosis with massive lymphadenopathy. Otolaryngol Head Neck Surg 1990;102:764-767.

$>10$ Pulsoni A, Anghel G, Falcucci P, et al: Treatment of sinus histiocytosis with massive lymphadenopathy (Rosai-Dorfman disease): report of a case and literature review. Am J Hematol 2002;69:67-71.
11 Payne JF, Srivastava SK, Wells JR, Grossniklaus HE: Rosai-Dorfman disease simulating nodular scleritis and panuveitis. Arch Ophthalmol 2011;129:518-520.

12 Malur PR, Bannur HB, Kodkany SB: Orbital Rosai-Dorfman disease: report of a case with fine needle aspiration cytology and histopathology. Acta Cytol 2007;51:581-582.

13 Avelino MA, Elias TG, Rezende RM, et al: Rosai-Dorfman disease as a differential diagnosis of nasosinusal polyposis in children. Braz J Otorhinolaryngol 2012;78:136.

14 Güven G, Ilgan S, Altun C, Gerek M, Gunhan O: Rosai Dorfman disease of the parotid and submandibular glands: salivary gland scintigraphy and oral findings in two siblings. Dentomaxillofac Radiol 2007;36 :428-433.

15 Illing EA, Halum SL: Rosai-Dorfman disease with isolated laryngeal involvement. Ear Nose Throat J 2012;91:439-440.

16 Chhabra S, Agarwal R, Garg S, Singh H, Singh S: Rosai-Dorfman disease: A case report with extranodal thyroid involvement. Diagn Cytopathol 2012;40:447-449.

17 Ji H, Zhang B, Tian D, et al: Rosai-dorfman disease of the lung. Respir Care 2012;57: 1679-1681.

18 Yontz L, Franco A, Sharma S, Lewis K, McDonough C: A case of Rosai-Dorfman disease in a pediatric patient with cardiac involvement. J Radiol Case Rep 2012;6:1-8.

19 Gwin K, Cipriani N, Zhang X, Schmidt R, Hyjek E: Bilateral breast involvement by disseminated extranodal Rosai-Dorfman disease. Breast J 2011;17:309-311.

20 Long E, Lassalle S, Cheikh-Rouhou R, et al: Intestinal occlusion caused by Rosai-Dorfman disease mimicking colonic diverticulitis. Pathol Res Pract 2007;203:233-237.
21 Romero Arenas MA, Singhi AD, Hruban RH, Cameron AM: Rosai-Dorfman disease (sinus histiocytosis with massive lymphadenopathy) of the pancreas: third reported occurrence. J Gastrointest Cancer 2012;43:626-629.

22 Tabata H, Hisasue S, Tsukamoto T: Extranodal Rosai-Dorfman disease of the kidney and bone. Int J Urol 2012;19:486-487.

23 Fernandopulle SM, Hwang JS, Kuick CH, et al: Rosai-Dorfman disease of the testis: an unusual entity that mimics testicular malignancy. J Clin Pathol 2006;59:325-327.

24 Castioni J, Mihaescu A, So AK: Sinus histiocytosis with massive lymphadenopathy (Rosai-Dorfman disease) and oligoarthritis. Joint Bone Spine 2011;78:641-643.

-25 Singh NG, Kapila K, Mathur S, Ray R, Verma $\mathrm{K}$ : Rosai-Dorfman disease manifesting as multiple subcutaneous nodules. Report of a case with diagnosis on a fine needle aspirate. Acta Cytol 2004;48:215-218.

26 Chow CP, Ho HK, Chan GC, Cheung AN, Ha SY: Congenital Rosai-Dorfman disease presenting with anemia, thrombocytopenia, and hepatomegaly. Pediatr Blood Cancer 2009;52: 415-417.

27 Kaur PP, Birbe RC, DeHoratius RJ: RosaiDorfman disease in a patient with systemic lupus erythematosus. J Rheumatol 2005;32: 951-953.

28 Agarwal A, Pathak S, Gujral S: Sinus histiocytosis with massive lymphadenopathy - a review of seven cases. Indian J Pathol Microbiol 2006;49:509-515.

29 Levine PH, Jahan N, Murari P, Manak M, Jaffe ES: Detection of human herpes virus 6 in tissues involved by sinus histiocytosis with massive lymphadenopathy (Rosai-Dorfman disease). J Infect Dis 1992;16:291-295. 
30 Mehraein Y, Wagner M, Remberger K, et al: Parvovirus B19 detected in Rosai-Dorfman disease in nodal and extranodal manifestations. J Clin Pathol 2006;59:1320-1326.

- 31 Al-Daraji W, Anandan A, Klassen-Fischer M, et al: Soft tissue Rosai-Dorfman disease: 29 new lesions in 18 patients, with detection of polyomavirus antigen in 3 abdominal cases. Ann Diagn Pathol 2010;14:309-316.

32 Lampert F, Lennert K: Sinus histiocytosis with massive lymphadenopathy: fifteen new cases. Cancer 1976;37:783-789.

-33 Wen CH, Huang MS, Wang SL, Su YC, Yang SF, Chai CY: Diagnostic value of computerized nuclear morphometry for the prediction of malignancy in liver fine needle aspiration cytology. Acta Cytol 2009;53:77-82.
34 Pambuccian SE, Becker RL Jr, Ali SZ, Savik K, Rosenthal DL: Differential diagnosis of Hürthle cell neoplasms on fine needle aspirates. Can we do any better with morphometry? Acta Cytol 1997;41:197-208.

35 Marchevsky AM, Hauptman E, Gil J, Watson C: Computerized interactive morphometry as an aid in the diagnosis of pleural effusions. Acta Cytol 1987;31:131-136.

36 Hughes-Jones NC, Wickramasinghe SN, Hatton SR: Normal haemoglobin, blood cells and haemopoiesis; in: Lecture Notes: Haematology, ed 8. Oxford, Wiley- Blackwell, 2009, pp $1-15$.

37 Krombach F, Münzing S, Allmeling AM, Gerlach JT, Behr J, Dörger M: Cell size of alveolar macrophages: an interspecies comparison. Environ Health Perspect 1997:105(suppl 5): 1261-1263.
38 Kram A, Peychewa M, Bachurska S, Domagala W: Morphometric distinction of signetring cell adenocarcinoma cells from foamy macrophages in gastric endoscopic biopsies. Pol J Pathol 2011;62:145-147.

39 Warnke RA, Weiss LM, Chan JK, Cleary M, Dorfman RM: Chronic histiocytic and dendritic cell proliferation; in: Tumors of Lymph Nodes and Spleen. Washington, Armed Forces Institute of Pathology, 1994, pp 358-360.

40 Iyer VK, Handa KK, Sharma MC: Variable extent of emperipolesis in the evolution of Rosai Dorfman disease: diagnostic and pathogenetic implications. J Cytol 2009;26:111116 